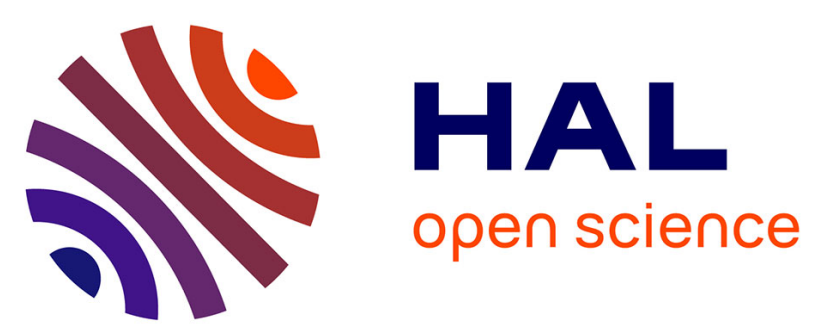

\title{
Water confined in mesoporous silica glasses: influence of temperature on adsorption / desorption hysteresis loop and fluid structure
}

Joël Puibasset, R.J.-M. Pellenq

\section{- To cite this version:}

Joël Puibasset, R.J.-M. Pellenq. Water confined in mesoporous silica glasses: influence of temperature on adsorption / desorption hysteresis loop and fluid structure. The European Physical Journal. Special Topics, 2007, 141 (1), pp.41-44. 10.1140/epjst/e2007-00013-3 . hal-03563057

\section{HAL Id: hal-03563057 https://hal.science/hal-03563057}

Submitted on 9 Feb 2022

HAL is a multi-disciplinary open access archive for the deposit and dissemination of scientific research documents, whether they are published or not. The documents may come from teaching and research institutions in France or abroad, or from public or private research centers.
L'archive ouverte pluridisciplinaire HAL, est destinée au dépôt et à la diffusion de documents scientifiques de niveau recherche, publiés ou non, émanant des établissements d'enseignement et de recherche français ou étrangers, des laboratoires publics ou privés. 
The headers will be insert by the Publisher

The headers will be insert by the Publisher

The headers will be insert by the Publisher

\title{
Water confined in mesoporous silica glasses: influence of temperature on adsorption / desorption hysteresis loop and fluid structure
}

\author{
J. PUIBASSET ${ }^{*}$, R. J.-M. PELLENQ ${ }^{2}$ \\ 1 Centre de Recherche sur la Matière Divisée, CNRS et Université d'Orléans, 1 bis rue de la \\ Férollerie, 45071 Orléans cedex 02, France \\ 2 Centre de Recherche en Matière Condensée et Nanosciences, CNRS, Campus de \\ Luminy, 13288 Marseille cedex 09, France
}

\begin{abstract}
In natural as well as industrial processes, water is frequently confined in silica porous materials with pore sizes in the nanometer scale. Understanding the confinement effects on the fluid properties is a fundamental issue, helpful to optimize the industrial processes. The molecular simulation is a powerful tool to study complex polar fluid like water at the atomic scale. The water adsorption / desorption properties in a mesoporous silica glass are investigated by means of Grand Canonical Monte Carlo simulations (GCMC). The SPC and PN TrAZ potential are used to describe water-water and water-silica interactions. The numerical sample of mesoporous silica glass (pore size: $3.6 \mathrm{~nm}$ ) was obtained by offlattice reconstruction, known to reproduce in a realistic way the geometrical complexity of high specific surface Vycor (pore size distribution, pore interconnections, etc).

The intermolecular potential is shown to reproduce the experimental data at $300 \mathrm{~K}$ (adsorption isotherm and isosteric heat of adsorption). The water structure is analyzed and confinement effects are emphasized. The temperature influence is studied: the hysteresis loop is shown to shrink with an increase in temperature.
\end{abstract}

\section{INTRODUCTION}

Adsorbed fluids exhibit many interesting features, like "capillary condensation" (appearance of a dense liquid-like state in mesoporous adsorbents for chemical potential lower than its bulk saturating value).[1-3] Despite many efforts to give a comprehensive theoretical analysis of the adsorption phenomena, there remain questions arising from the complexity of the real materials: topological and morphological disorder, surface roughness, surface chemistry, large pore size distribution, interconnections between pores, etc. The development of molecular simulations is a powerful tool to take into account these heterogeneities.

This molecular simulation study focuses on the water adsorption in mesoporous Vycor-like silica glasses, with applications in geophysics, pharmaceutics, industry, or environment. The adsorbent was previously constructed by off-lattice methods to mimic the micro- and meso-textural properties of real

*puibasset@cnrs-orleans.fr 
Vycor [4-6]. Whereas most of the previous studies focused on the dynamical or structural properties of confined water [7-11], this one focuses on the thermodynamic properties which are actually essential prior to a molecular dynamics study for instance (to "equilibrate" the initial configuration). The Grand Canonical Monte Carlo (GCMC) method has been used since it mimics a real adsorption experiment where the temperature and the chemical potential of the fluid (or the pressure of the gas) are fixed. The water adsorption isotherms at $300 \mathrm{~K}, 350 \mathrm{~K}, 400 \mathrm{~K}, 500 \mathrm{~K}$ and $650 \mathrm{~K}$ are calculated in this numerical mesoporous glass sample, as well as the isosteric heat of adsorption, and compared to experiments when possible. The hysteresis diagram is also proposed.

\section{COMPUTATIONAL DETAILS}

The atomistic Vycor-like mesoporous structure considered in this study has been generated by offlattice reconstruction algorithm [4,5] This numerical sample reproduces quite well textural properties of real Vycor [6]. The surface chemistry is realistic (hydroxyl groups). The porosity of the sample is 0.28 , the density $1.56 \mathrm{~g} / \mathrm{cm}^{3}$, the specific surface area $210 \mathrm{~m}^{2} / \mathrm{g}$, the mean pore diameter $36 \AA$ (from chord distribution), and $\mathrm{OH}$ surface density $7 \mathrm{OH} / \mathrm{nm}^{2}$, all in agreement with experimental values: $0.28,1.50 \mathrm{~g} / \mathrm{cm}^{3}, 200 \mathrm{~m}^{2} / \mathrm{g}$, and around $7 \mathrm{OH} / \mathrm{nm}^{2}$ if out-gassed around $400^{\circ} \mathrm{C}[12,13]$.

The adsorbed water is described by the SPC model [14] which reproduces well the thermodynamic and structural properties around ambient temperature [15]. The interaction of water with $\mathrm{Si}, \mathrm{O}$ and (surface) $\mathrm{H}$ Vycor species is assumed to remain weak, in the physisorption energy range. In this work, we have used a TrAZ form of the original PN-type potential function as reported for adsorption of rare gases and nitrogen and water in silicalite-1. [16-20] Minimal image convention is adopted to calculate all interactions.

The adsorption isotherms are calculated with the Grand Canonical Monte Carlo (GCMC) technique [21]. New configurations are generated every $10^{4}$ Monte Carlo steps so that they are de-correlated. For each chemical potential value the averages are performed over approximately $10^{6}$ trials per molecule.

\section{RESULTS AND DISCUSSION}

In order to validate the molecular model, a first study [22] was performed at room temperature $(300 \mathrm{~K})$. The numerical results have been compared to two set of experimental data found in the literature. The first one is a gravimetric measurement by T. Takei, et al. [23] in a 7930 Vycor sample characterized by nitrogen adsorption (pore size around $4.72 \mathrm{~nm}$ in diameter). The other one has been obtained by Markova, et al. [24] with a double twin microcalorimeter, in a 7930 Vycor glass (pore size between 4 and $7 \mathrm{~nm}$ ). The low pressure results are characteristic of hydrophilic surfaces (large uptake of water molecules). The good agreement between the simulation results with the experimental data validates the good transferability of the potential model used in this study. Note that this comparison is performed at room temperature. It is however expected that the potential remains valid at high temperatures.

The whole adsorption / desorption isotherms at $300 \mathrm{~K}, 350 \mathrm{~K}, 400 \mathrm{~K}, 500 \mathrm{~K}$, and $650 \mathrm{~K}$ are plotted in figure 1a (normalized to the surface area of the substrate exposed to water vapor, in $\mu \mathrm{mol} / \mathrm{m}^{2}$ ). The results are given as a function of the chemical potential of water imposed by the GCMC simulation instead of pressure. It is important to note that this chemical potential does not contain the ideal rotational contribution $-k T(-4.09+3 / 2 \ln T)$, with $T$ in Kelvin [25]. The high temperature $(650 \mathrm{~K}$ and $500 \mathrm{~K}$ ) isotherms are reversible (supercritical), whereas the low temperature cases present large hysteresis (type IV isotherm in the IUPAC classification). The steep rises are associated to the capillary condensation of water in the mesoporosity of the Vycor glass. These simulation results are in 
qualitative agreement with experimental data, with an asymmetric adsorption / desorption hysteresis characteristic of disordered and interconnected pores [1,26,27].
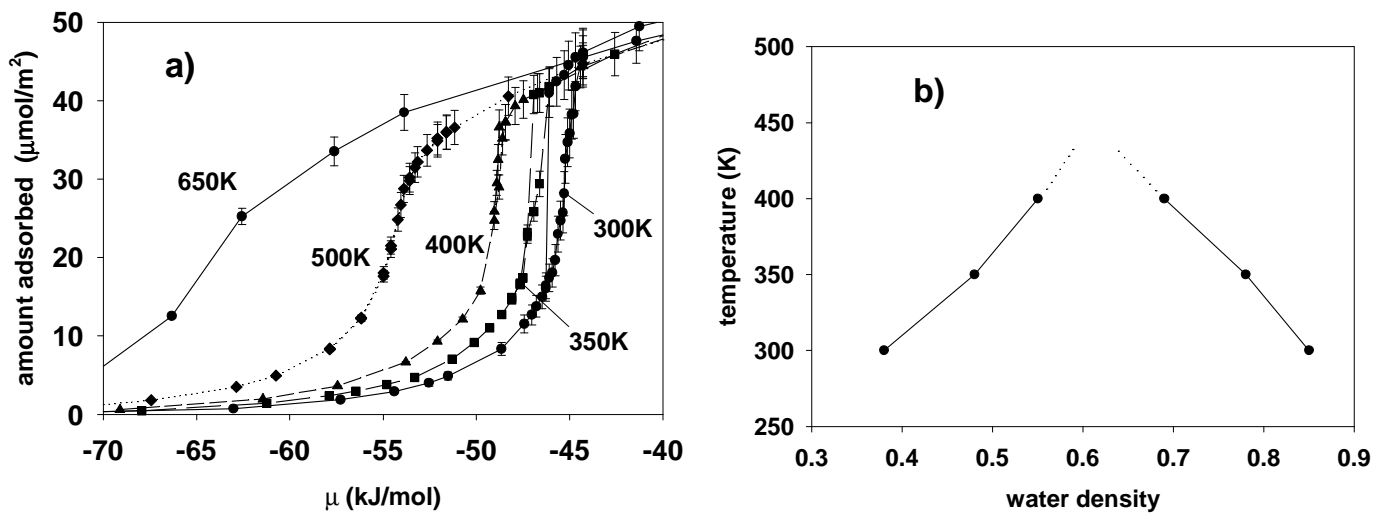

Figure 1. a: water adsorption / desorption isotherms in Vycor versus chemical potential at different temperatures. Lines are guides to the eye. b: diagram of water confined in mesoporous silica.

The figure $1 \mathrm{~b}$ gives the hysteresis diagram of confined water. This diagram gives, for each temperature, the densities of the liquid and gas branches at coexistence. The adsorption / desorption isotherms and the hysteresis diagram show that the pseudo-critical temperature (disappearance of the hysteresis loop) is lower than the bulk critical temperature since the $\mathrm{T}=500 \mathrm{~K}$ isotherm is reversible. An estimate of this temperature gives a value around $450 \mathrm{~K}$ in our simulation box. This is the first estimation of the pseudo-critical temperature of water in a Vycor-like structure.

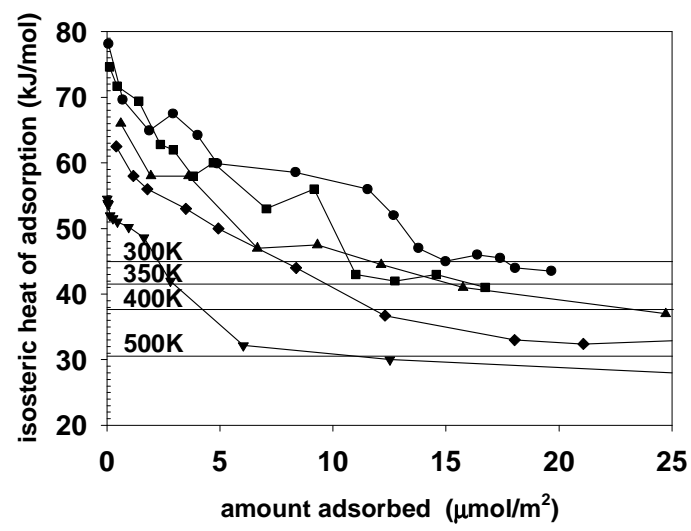

Figure 2. Isosteric heat of adsorption versus water coverage at different temperatures $(300,350,400$, 500 and $650 \mathrm{~K}$ from top to bottom); symbols: this work; horizontal lines: latent heat of vaporization of bulk water $[28,29]$.

The figure 2 presents the results for the isosteric heat of adsorption, which give information on the water silica affinity. The horizontal lines represent the bulk values. As can be seen, for large water amounts, the isosteric heat reaches the bulk values, while at low coverage the values are larger, which shows strong water silica affinity (hydrophilic adsorbent). This behavior is quantitatively in agreement with experimental data $(80 \mathrm{~kJ} / \mathrm{mol}$ at ambient temperature). 


\section{Acknowledgments}

The Institut de Développement des Ressources en Informatique Scientifique (IDRIS-CNRS, Orsay, France) is gratefully acknowledged for the CPU grant $n^{\circ} 051153$

\section{References}

[1] Gelb, L. D.; Gubbins, K. E.; Radhakrishnan, R.; Sliwinska-Bartkowiak, M. Rep. Prog. Phys., 62 (1999) 1573-1659.

[2] Gregg, S. J.; Sing, K. S. W. Adsorption, Surface Area and Porosimetry Academic Press, New York, 1982).

[3] Rouquerol, F.; Rouquerol, J.; Sing, K. S. W. Adsorption by Powders and Porous Solids Academic Press, London, 1999).

[4] Levitz, P. Adv. Colloid Interface Sci., 76/77 (1998) 71-106.

[5] Levitz, P.; Ehret, G.; Sinha, S. K.; Drake, J. M. J. Chem. Phys., 95 (1991) 6151-6161.

[6] Pellenq, R. J.-M.; Rousseau, B.; Levitz, P. E. Phys. Chem. Chem. Phys., 3 (2001) 1207-1212.

[7] Lee, S. H.; Rossky, P. J. J. Chem. Phys., 100 (1994) 3334-3345.

[8] Spohr, E.; Trokhymchuk, A.; Henderson, D. J. Electroanal. Chem., 450 (1998) 281-287.

[9] Rovere, M.; Ricci, M. A.; Vellati, D.; Bruni, F. J. Chem. Phys., 108 (1998) 9859-9867.

[10] Hartnig, C.; Witschel, W.; Spohr, E.; Gallo, P.; Ricci, M. A.; Rovere, M. J. Mol. Liquids, 85 (2000) 127-137.

[11] Gallo, P.; Ricci, M. A.; Rovere, M. J. Chem. Phys., 116 (2002) 342-346.

[12] Landmesser, H.; Kosslick, H.; Storek, W.; Fricke, R. Solid State Ionics, 101-103 (1997) 271277.

[13] Low, M. J. D.; Ramasubramanian, N. J. Phys. Chem., 71 (1967) 730-737.

[14] Berendsen, H. J. C.; Postma, J. P. M.; van Gunsteren, W. F.; Hermans, J., in Intermolecular Forces (B. Pullman, Dordrecht: Reidel, 1981), pp. 331.

[15] Jorgensen, W. L.; Chandrasekhar, J.; Madura, J. D.; Impey, R. W.; Klein, M. L. J. Chem. Phys., 79 (1983) 926-935.

[16] Pellenq, R. J.-M.; Nicholson, D. J. Phys. Chem., 98 (1994) 13339-13349.

[17] Pellenq, R. J.-M.; Nicholson, D. Mol. Phys., 95 (1998) 549-570.

[18] Puibasset, J.; Pellenq, R. J.-M. J. Chem. Phys., 118 (2003) 5613-5622.

[19] Puibasset, J.; Pellenq, R. J.-M. J. Chem. Phys., 119 (2003) 9226-9232.

[20] Puibasset, J.; Pellenq, R. J.-M. J. Phys.: Condens. Matter, 16 (2004) S5329-S5343.

[21] Nicholson, D.; Parsonage, N. G. Computer simulation and the statistical mechanics of adsorption Academic Press, London, 1982).

[22] Puibasset, J.; Pellenq, R. J.-M. J. Chem. Phys., 122 (2005) 094704.

[23] Takei, T.; Yamazaki, A.; Watanabe, T.; Chikazawa, M. J. Colloid Interface Sci., 188 (1997) 409-414.

[24] Markova, N.; Sparr, E.; Wadsö, L. Thermochim. Acta, 374 (2001) 93-104.

[25] Frenkel, D.; Smit, B. Understanding Molecular Simulation Academic Press, London, 1996).

[26] Takei, T.; Musaka, K.; Kofuji, M.; Fuji, M.; Watanabe, T.; Chikazawa, M.; Kanazawa, T. Colloid and Polymer Science, 278 (2000) 475-480.

[27] Burgess, C. G. V.; Everett, D. H.; Nuttall, S. Pure Appl. Chem., 61 (1989) 1845-1852.

[28] Errington, J. R.; Panagiotopoulos, A. Z. J. Phys. Chem. B, 102 (1998) 7470-7475.

[29] Vorholz, J.; Harismiadis, V. I.; Rumpf, B.; Panagiotopoulos, A. Z.; Maurer, G. Fluid Phase Equilibria, 170 (2000) 203-234. 